\title{
Perancangan Aplikasi Pembelajaran Steganografi Algoritma Least Signification Bit Dengan Metode Computer Assisted Intruction
}

\author{
Aperius Frediks Gulo \\ STMIK Budi Darma, Jl. Sisingamangaraja No. 338 Medan, Sumatera Utara, Indonesia \\ http://stmik-budidarma.ac.id // Email : aperiusfrediksgulo@gmail.com
}

\begin{abstract}
Steganography which is an art and technique that can be used to do digital data security or the process of hiding secret messages in the form of text in other forms so that it is not easily known by others. Least Significant Bit (LSB) is one of the steganography methods that is used to insert or hide messages by replacing rows of rear bits.

From the classroom observations it was revealed that generally pay attention when the teacher explains the subject matter and gives practice questions. But communication in the classroom generally occurs in one direction which is dominated by the teacher or tutor. This theory learning often makes students bored when compared to practical activities that are directly carried out at the computer or with other technological tools. By applying the Computer Assisted Intruction (CAl) learning model, it uses strategic learning methods by providing material, training and games that greatly assist the process of delivering material by the instructor. Mobile-based Least Significant Bit (LSB) Algorithm Learning Application using adobe flash CS6, can be an alternative learning method. To overcome these problems and see the ownership of smartphones in Indonesia is almost evenly shared by students and the community. Then this application can support these learning activities.
\end{abstract}

Keywords: Steganography, Least Significant Bit (LSB), Computer Assisted Instruction (CAI)

\section{PENDAHULUAN}

Steganografi merupakan salah seni dan teknik yang dapat digunakan untuk melakukan pengamanan data digital atau proses penyembunyian pesan rahasia berupa teks dalam bentuk lain sehingga tidak mudah diketahui oleh orang lain. Steganografi banyak dimanfaatkan untuk mengirim pesan melalui jaringan internet tanpa diketahui orang lain dengan menggunakan media digital berupa file gambar, audio maupun video. Ada dua proses utama dalam steganografi yaitu penyisipan (embedding) dan penguraian (extraction) pesan atau informasi dalam media penampung (cover). Embedding merupakan proses menyisipkan pesan atau informasi ke dalam media cover, sedangkan extraction adalah proses menguraikan pesan yang tersembunyi dalam gambar stego [11].

Least Significant Bit (LSB) merupakan salah satu metode steganografi yang digunakan untuk menyisipkan atau menyembunyikan pesan dengan mengganti deretan bit-bit belakang atau bit yang paling kanan pada pixel gambar yang menyusun file tersebut. Dengan melakukan penggantian pada bit-bit belakang pada citra maka perubahan tingkat intensitas tidak mudah dapat terdeteksi pada mata manusia.
Peranan komputer, khususnya dalam bidang perangkat lunak, semakin membantu manusia dalam menyelesaikan masalah. Penyampaian materi pembelajaran dengan menggunakan aplikasi merupakan salah satu solusi dalam menyelesaikan masalah di atas, aplikasi pembelajaran dapat diartikan sebagai salah satu sarana penyampaian pembelajaran yang lebih interaktif dan inovatif serta terintegrasi yang mencakup teks, gambar, suara, video atau animasi dengan memanfaatkan komputer. Pemanfaatan aplikasi pembelajaran berbasis komputer telah banyak memberikan pengaruh yang positif bagi para peserta didik atau user serta dapat memicu daya tarik peserta untuk mempelajari materi ajar secara berulang-ulang ${ }^{[6] .}$

Computer Assisted Intruction (CAI) merupakan salah satu metode pembelajaran yang digunakan untuk pengajaran yang menggunakan komputer sebagai alat bantu, sehingga materi yang diajarkan lebih mudah dipahami oleh pesarta didik atau user terhadap materi yang disampaikan oleh pengajarnya. Penggunaan metode Computer Asisted Intruction (CAl) peran pengajar tidak semuanya dihilangkan dan komputer hanya berperan sebagai pendamping pengajar dalam menyampaikan materi ${ }^{[10]}$. 
Berdasarkan latar belakang masalah, maka yang menjadi perumusan masalah adalah:

1. Bagaimana proses penyajian materi steganografi algoritma Least Significant Bit (LSB) ?

2. Bagaimana menerapkan metode Computer Assisted Instruction (CAl) pada proses pembelajaran steganografi algoritma Least Significant Bit (LSB) ?

3. Bagaimana merancang aplikasi pembelajaran LSB dengan menerapkan metode Computer Assisted Instruction (CAI) berbasis android?

Berdasarkan penelitian ini, yang menjadi tujuan dan manfaat adalah sebagai berikut: Mengetahui proses penyampaian materi Least Significant Bit (LSB) kepada peserta didik oleh pengajar melalui aplikasi media pembelajaran. Menerapkan metode pembelajaran Computer Assisted Instruction (CAI) pada proses pembelajaran materi Least Significant Bit (LSB). Merancang sebuah aplikasi pembelajaran LSB (Least Significant Bit ) dengan metode Computer Assisted Instruction (CAI) berbasis android yang membantu peserta didik lebih memahami materi Least Significant Bit (LSB)

Adapaun manfaat yang diharapkan berdasarkan tujuan penelitian yang telah disebutkan di atas, maka penelitian ini mempunyai manfaat sebagai berikut : Mendapatkan materi steganografi Algoritma Least Significant Bit (LSB) yang disusun selama proses pembelajaran dengan Metode CAI. Membantu pengajar atau tutor pada proses penyampaian materi steganografi tentang alogiritma Least Significant Bit kepada peserta didik. Dapat sebagai salah satu alternatif media pembelajaran Steganografi Algoritma Least Significant Bit yang menarik dan mudah dipahami oleh peserta didik .

\section{LANDASAN TEORI \\ 2.1. Pembelajaran}

Menurut Rochman Nata Wijaya (2011:85) Pembelajaran adalah proses interaksi peserta didik dengan pendidik dan sumber belajar pada suatu lingkungan belajar. Pembelajaran merupakan bantuan yang diberikan pendidik agar dapat terjadi proses pemerolehan ilmu dan pengetahuan, penguasaan kemahiran dan tabiat, serta pembentukan sikap dan kepercayaan pada peserta didik. Dengan kata lain, pembelajaran adalah proses untuk membantu peserta didik agar dapat belajar dengan baik ${ }^{[7] \text {. }}$

\subsection{Computer Assisted Instruction (CAI)}

Computer Assisted Instruction (CAI) yang artinya komputer digunakan untuk membantu proses pembelajaran dalam menyampaikan materi yang sudah diprogramkan. Di Computer Assisted Instruction (CAl) peran guru tidak semuanya dihilangkan dan komputer hanya berperan sebagai pendamping guru dalam menyampaikan materi. Komputer sebagai media untuk menyampaikan materi pembelajaran atau informasi, petunjuk dalam menyelesaikan soal-soal latihan yang juga sekaligus sebagai penilai. Model CAI di bedakan menjadi 5 jenis yaitu :tutorial, latihan dan praktik, pemecahan masalahan, simulasi, dan permainan ${ }^{[10]}$

1. Tutorial

Memakai teori dan strategi pembelajaran dengan memberikan materi, pertanyaan, contoh, latihan dan kuis agar murid dapat menyelesaikan suatu masalah, tujuannya adalah membuat siswa memahami suatu konsep yang baku. Akan tetapi bila sistem ini disertai dengan modul remedial. Maka bila gagal, siswa akan diberikan remedial terhadap topic yang ia salah saja.

2. Latih dan praktik (Drill and Practice)

Latih dan praktik merupakan metode pengajaran yang dilakukan dengan memberikan latihan yang berulang-ulang, tujuannya yaitu siswa akan lebih terampil, cepat, dan tepat dalam melakukan suatu keterampilan mengetik atau menjawab soal hitungan.

3. Pemecahan masalah (Evaluasi)

Pemecahan masalah adalah suatu metode mengajar yang mana siswanya diberi soalsoal, s lalu diminta pemecahannya, tujuannya menganalisis masalah dan memecahkan masalah tersebut.

4. Simulasi

Proses simulasi biasanya digunakan untuk mengajarkan proses atau konsep yang tidak secara mudah dapat dilihat (abstrak), seperti bagaimana bekerjanya bekerjanya proses ekonomi, atau bagaimana hubungan antara supply and demand terhadap harga dan seterusnya.

5. Permainan

Materi dari permainan hal yang ingin diajarkan, sekaligus ia juga berperan sebagai motivator. Pendekatan motivasi, dibedakan antara : motivasi intrinsic yaitu tidak ada reward diluar atau tanpa reward seperti "point" misalnya siswa menyenangi pemainan tersebut.

\subsection{Steganografi}

Kata steganografi berasal dari bahasa Yunani steganos yang artinya tersembunyi atau terselubung dan graphein artinya menulis. 
Steganografi (steganography) adalah proses menyimpan pesan rahasia berupa teks dalam bentuk lain sehingga tidak mudah diketahui oleh orang lain. steganografi (steganography) berasal dari bahasa Yunani yaitu steganos, yang artinya "tersembunyi" atau "terselubung", dan graphein, yang artinya "menulis" sehingga kurang lebih artinya adalah "menulis (tulisan) terselubung" Steganografi juga dapat diartikan ilmu dan seni menyembunyikan pesan di dalam pesan lain sehingga keberadaan pesan yang pertama tidak diketahui ${ }^{[3]}$

\subsection{Least Significant Bit (LSB)}

Least Significant Bit (LSB) adalah metode steganografi yang paling sederhana dan paling mudah diimplementasikan. Setiap piksel di dalam citra berukuran 1 sampai 3 byte. Susunan didalam sebuah byte $(1$ byte $=8$ bit $)$, metode yang digunakan untuk menyembunyikan pesan pada media digital contohnya, pada berkas image pesan dapat menyembunyikan dengan menggunakan cara menyisipkan teks pada bit rendah atau bit yang paling kanan (LSB) pada data piksel yang menyusun file tersebut. Pada berkas bitmap 24 bit, setiap piksel (titik) pada gambar tersebut terdiri dari susunan tiga warna merah, hijau dan biru (RGB) yang masing-masing disusun oleh bilangan 8 bit (byte) dari 0 sampai 255 atau dengan format biner 00000000 sampai 11111111. Dengan demikian, pada setiap piksel berkas bitmap 24 bit kita dapat menyisipkan 3 bit data ${ }^{[11] .}$

\section{PEMBAHASAN}

\subsection{Analisa Penyajian Materi Steganografi}

Penyampaian materi steganografi algoritma Least Significant Bit terhadap peserta didik di kelas, sering mengalami masalah karana kurangnya pemahaan terhadap materi tersebut. Jika menggunakan teknik yang lama seperti mengajarkan peserta didik secara langsung dengan menggunakan media papan tulis akan sulit bagi peserta didik tersebut untuk dapat memahami apa yang diajarkan oleh pengajar karena setiap peserta didik memiliki karakteristik yang berbeda-beda, misalnya daya tangkap dalam menyerap pelajaran ataupun motivasi belajar peserta didik tersebut. Selain itu, faktor eksternal yang juga dapat mempengaruhi kegiatan pembelajaaran tersebut, misalnya cara pengajar dalam menyampaikan pelajaran ataupun lingkungan yang kurang nyaman untuk belajar.

\subsection{Penerapan Metode Computer Assisted Instruction}

Computer Assisted Instruction adalah perangkat lunak yang berisi materi pelajaaran yang digunakan sebagai alat bantu anak didik dalam proses pembelajaran dengan cara berinteraksi dengan sistem komputer. Metode Computer Assisted Instruction (CAl) yang diterapkan dalam pembelajaran ini adalah :

1. Totorial

Materi yang akan disajikan dalam totorial ini adalah tentang silabus atau pengenalan materi steganografi dan topiktopik pembahasan mengenai algoritma Least Significant Bit. Pada pertemuan pertama ini disajikan silabus tentang materi yang akan disampakan, dan pada pertemuan selanjutnya disampaikan penjelasan tentang materi yang ada pada silabus.

Tabel 1 Materi Yang Disajikan

\begin{tabular}{|c|c|}
\hline No & Materi \\
\hline 1 & Pengertian Steganografi \\
\hline 2 & Algoritama Least Significant Bit \\
\hline
\end{tabular}

Adapun contoh tutorial dalam aplikasi pembelajaran ini adalah diuraikan sebagai berikut :

a. Materi Pengenalan Steganografi

Materi pada bagian ini merupakan materi-materi yang memberikan penjelasan tentang apa pengertian steganografi dan jenis-jenis steganografi.

Adapun isi dari materi ini adalah sebagai berikut :

Defenisi :

Steganografi (steganography) adalah proses menyimpan pesan rahasia berupa teks dalam bentuk lain sehingga tidak mudah diketahui oleh orang lain. steganografi (steganography) berasal dari bahasa Yunani yaitu steganos, yang artinya "tersembunyi" atau "terselubung", dan graphein, yang artinya "menulis" sehingga kurang lebih artinya adalah "menulis (tulisan) terselubung" Steganografi juga dapat diartikan ilmu dan seni menyembunyikan pesan di dalam pesan lain sehingga keberadaan pesan yang pertama tidak diketahui.

b. Algoritma Least Significant Bit (LSB) Defenisi :

Least Significant Bit (LSB) adalah metode menyembunyikan dengan menggunakan cara menyisipkannya pada bit rendah atau bit yang paling kanan (Least Significant Bit) pada data pixel yang menyusun file tersebut. 
2. Latihan (Drill and Practice)

Materi yang telah disampaikan akan diuji melalui pertanyaan-pertanyaan, dimaksudkan agar peserta didik lebih memperhatikan materi serta untuk menilai sejauh mana kemampuan peserta didik untuk mengingat pelajaran tersebut. Pertanyaan disajikan dalam bentuk pilihan ganda.

Adapun contoh dari bentuk dari Latihan yaitu sebagai berikut :

1. Suatu teknik mengamankan data dengan menyisipkan pesan rahasia pada media lain adalah pengeritian dari ...
a. Kriptografi
b. Steganografi
c. Watermaking
d. Salah Semua

2. Pengamaan pesan dengan cara menyisipkannya pesan pada bit rendah atau bit yang paling kanan pada data pixel yang menyusun file tersebut merupakan alogoritma...
a. Least Significati Bit
b. Algorithms and Transformation
c. Redundant Pattern Encoding
d. Spread Spectrum method

Respon peserta didik terhadap pertanyaan tersebut akan menentukan score yang dicapai. Jika responya (a) dan (a) merupakan jawaban yang benar maka nilai atau skor akan ditambah dan dilanjutkan pada pertanyaan selajutnya. Jika jawaban (a) merupakan jawaban yang salah tidak ada pengurangan nilai dan pertanyaan selanjutnya akan ditampilkan. Demikian seterusnya hingga seluruh soal dijawab.

3. Evaluasi atau Pemecahan Masalah Pemecahan masalah adalah suatu metode mengajar yang mana siswanya diberi soal-soal, lalu diminta pemecahannya, tujuannya menganalisis masalah dan memecahkan masalah tersebut.

Adapun contoh dari pemecahan masalah yaitu :

Least Significant Bit adalah cara menyisipkan atau menyembunyikan pesan dengan mengganti deretan bit-bit belakang atau bit yang paling kanan pada pixel gambar yang menyusun file tersebut. Pemecahan Masalah :

(00100111 11101001 11001000)

(0010011111001000 11101001)

(11001000 0010011111101001$)$

Jika diinginkan untuk menyembunyikan karakter A (100000011) dihasilkan:

(00100111 1110100ㅁ 1100100ㅁ)
(0010011무 1100100ㅁ 11101000)

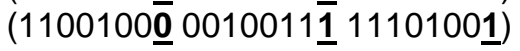

Gambar Deretan Bit-bit Belakang yang telah disisipkan Karakter A.

4. Simulasi

Proses simulasi digunakan untuk mengajarkan proses atau konsep yang tidak secara mudah dapat dilihat (abstrak), seperti bagaimana pemahaman tentang pengertian steganografi.

Contoh :

Pemahanan tentang pengertian steganografi.

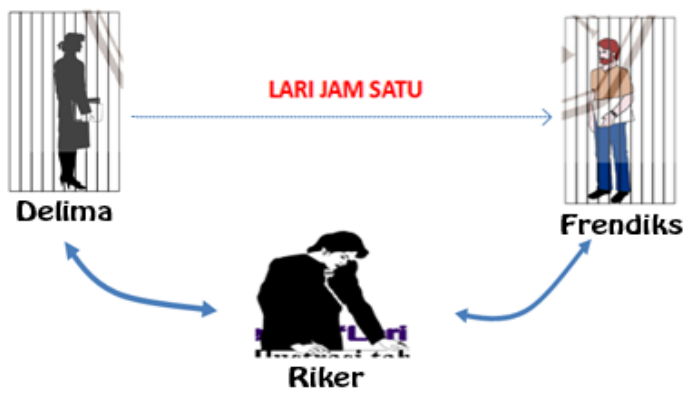

Gambar 1 Simulasi Steganografi

Delima Mengirim Pesan Ke Riker Untuk Disampaikan Kepada Frendiks : Lupakan Asal Rumur Itu Ambil Manfaatnya Setelah Aku Tutup Usia

5. Permainan (Game)

Permainan yang disajian pada bagian ini yaitu pertanyaan yang menunjang pengetahuain siswa terhadap materi steganografi algoritma least significant bit. Pada permainan ini ada dua aspek yang diharapkan ada yaitu :

a. Umpan balik

Setelah sistem memberikan pertayaan dan user merespon dengan cara menjawab pertayaan tersebut maka sistem meberikan umpan balik berupa peringatan bahwa respon tersebut benar atau salah.

b. Penilaian

Aplikasi harus dilengkapi dengan aspek penilaian. Untuk mengetahui seberapa jauh user dalam memahami materi yang dipelajari. Pada aplikasi ini penilaian diberikan berupa persentase, dimana ketika user selesai menjawab seluruh pertanyaan maka sistem memberikan persentase jawaban benar dan salah, kemudian sistem memberikan komentar berupa skor.

\section{ALGORITMA DAN IMPLEMENTASI 4.1. Algoritma}

Algoritma juga dapat didefenisikan sebagai urutan langkah-langkah logis penyelesaian 
masalah yang disusun secara sistematis. Langkah-langkah tersebut harus logis, berarti nilai kebenarannya harus dapat ditentukan benar atau salahnya.

Algoritma pada Aplikasi Pembelajaran Steganografi Algoritma Least Significant Bit menggunakan metode Computer Assisted Instruction (CAI) berbasis Mobile yang dirancang oleh penulis adalah :

1. Algoritma Menu Utama

Menu Utama digunakan untuk menampilkan hasil dari penggunaan property yang telah disedikan berdasarkan menu utama. Algoritma Menu Utama dapat diuraikan sebagai berikut :

Input : tutorial, soal latihan, evaluasi, simulasi, game,

Output : tampil tutorial, tampil latihan, tampil evaluasi, tampil simulasi, tampil game.

Proces :

If tutorial = tutorial maka

Tampilkan tutorial

Else If soal latihan = soal latihan maka Tampilkan soal latihan

Else If evaluasi = evaluasi maka Tampilkan evaluasi

Else If simulasi = simulasi maka Tampilkan simulasi

Else If game = game maka Tampilkan game

Else If keluar = keluar maka Keluar aplikasi end

\subsection{Implementasi Program}

Pembelajaran Steganografi Algoritma Least Significant Bit (LSB) yang telah dirancang merupakan aplikasi pembelajaran yang menggunakan bahasa pemrograman flash actionscript 3.0, dimana untuk mengetik listing program dilakukan pada Adobe Flash CS6 yang merupakan perangkat lunak editor untuk pembuatan aplikasi multimedia. Untuk menjalankan aplikasi yang dibuat menggunakan handphone yang bersistem operasi Android dengan terlebih dahulu menginstal aplikasi vitur tambahan yaitu Adobe Air. Vitur tambahan itu dapat di didowload pada Play Store.

1. Halaman Awal

Halaman Awal menampilkan judul aplikasi pembelajaran Stegga Algoritma Least Significant Bit (LSB) dengan metode Computer Assisted Instruction (CAI). Halaman Menu utama menampilkan pilihan menu yang tersedia pada program.

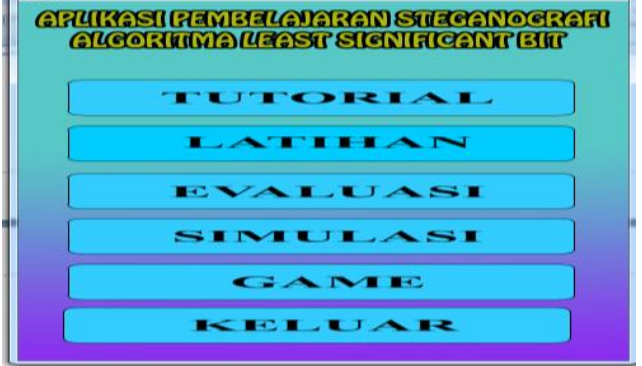

Gambar 2. Tampilan Menu Utama

1. Halaman Tutorial

Pada halaman ini terdapat tutorial tentang Steganografi algoritma Least Significant Bit.

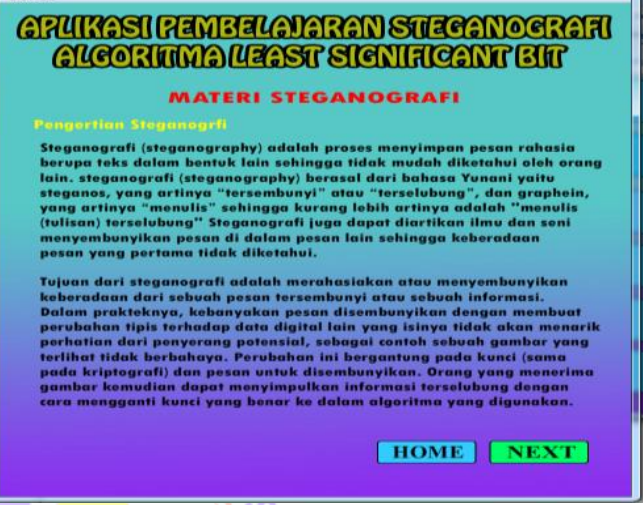

Gambar 3. Tampilan Tutorial

2. Halaman Latihan

Pada halaman soal latihan ini terdapat soal latihan tentang steganografi algoritma Least Significant Bit (LSB).

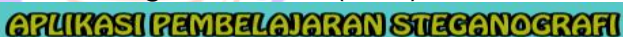
QนGORाTMDLEAST SI GNIFICANT BIT

$$
\text { LATIHAN (DRILL AND PRACTICE) }
$$

PILIHAN GANDA

1. Suatu teknik mengamankan data dengan menyisipkan pesan rahasia pada media lain adalah pengeritian dari ...
[A] Kriptografi
[B] Steganografi
[C] Watermaking
D] Salah Semua

\section{Gambar 4. Tampilan Soal Latihan}

3. Halaman Evaluasi

Pada halaman Evaluasi ini terdapat evaluasi steganografi algoritma Least Significant Bit. 


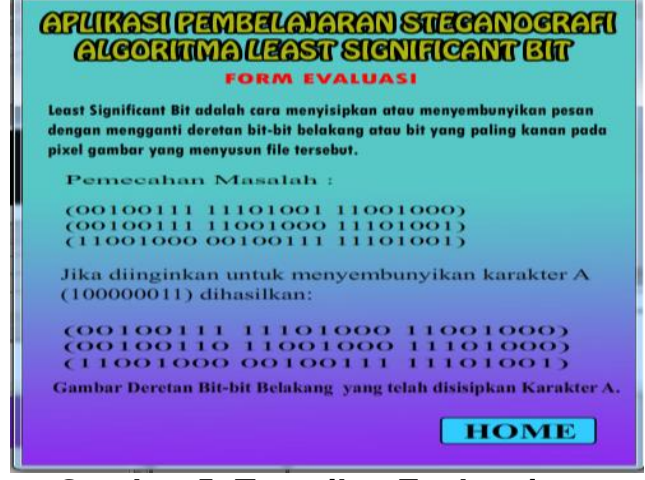

Gambar 5. Tampilan Evaluasi

4. Halaman Simulasi

Pada halaman simulasi ini terdapat simulasi tentang steganografi algoritma Least Significant Bit.

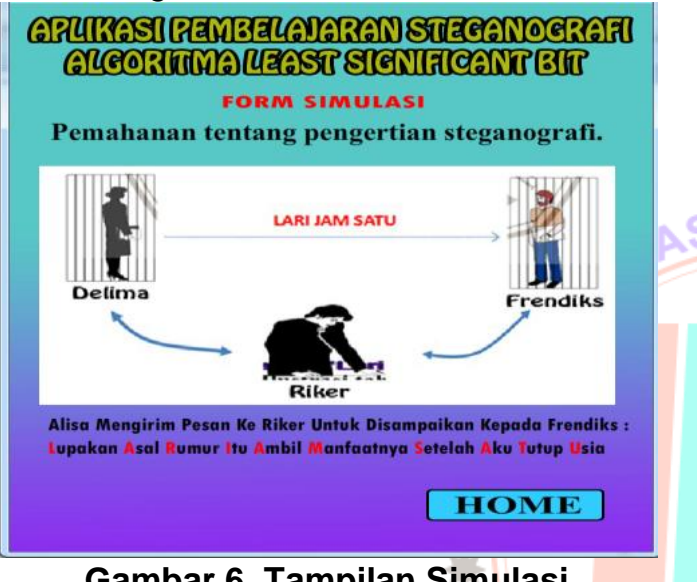

Gambar 6. Tampilan Simulasi

5. Halaman Game

Pada halaman game ini terdapat game sebagai pemberian pembahaan lebih dan sekaligus mengasah otak dalam pembelajaran.

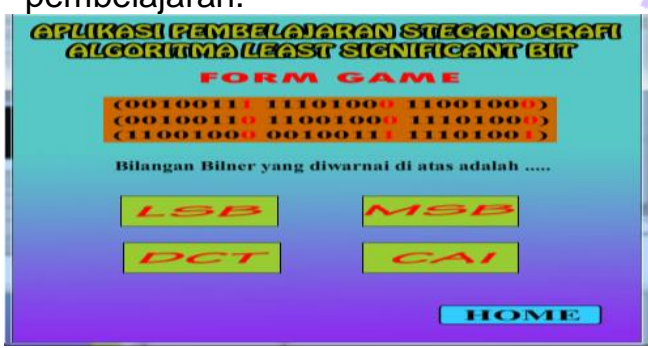

Gambar 8 Tampilan Game

\section{KESIMPULAN DAN SARAN}

\subsection{Kesimpulan}

Adapun yang menjadi kesimpulan dari penulisan penelitian ini adalah sebagai berikut :

1. Penyajian materi steganografi algoritma Least Significant Bit (LSB) yang disusun selama proses pembelajaran dapat disajikan dengan menggunakan sebuah aplikasi pembelajaran.

2. Penerapan metode Computer Assisted Instruction (CAI) pada pembelajaran
Steganografi Algoritma Least Significant Bit (LSB) dapat membantu pengajar atau tutor pada proses penyampaian materi steganografi kepada peserta didik.

1. Aplikasi pembelajaran yang dibangun dapat sebagai salah satu alternatif media pembelajaran Steganografi Algoritma Least Significant Bit yang menarik dan mudah dipahami oleh peserta didik.

\subsection{Saran}

Adapun yang menjadi saran-saran dalam penulisan penelitian ini adalah sebagai berikut :

1. Aplikasi pembelajaran steganografi algoritma Least Significant Bit (LSB) dapat di kembangkan di perangkat Android diatas versi 4.1 maupun dibawah versi 4.1

2. Aplikasi Pembelajaran Steganografi Algoritma Least Significant Bit (LSB) yang telah dibuat masih memiliki kelemahan, oleh karenanya disarankan bagi para pembaca agar dapat mengembangkannya, baik dari tampilan, simulasi ataupun metodenya.

3. Aplikasi yang dibangun agar dapat dikembangkan bersifat online sehingga dapat didapatkan langsung pada Play Store.

\section{DAFTAR PUSTAKA}

1. Abdul Kadir, "Pengenalan Sistem Informasi". Yogyakarta , Andi Offset, 2011.

2. Adi Nugroho, "Rekayasa Perangkat Lunak", Modula, Yogyakarta, 2011

3. Efvy Zam,"Keamanan Data",Bandung, Andi, 2013

4. Jogiyanto,H.M. "Sistem Teknologi InFormasi". Yogyakarta, Andi Offset, 2010.

5. Mulyadi, "Perancangan Sistem", Yogyakarta, Andi Offset, 2011

6. Wijaya Nata,"Aplikasi Pembelajaran", Informatika, Bandung, 2011

7. Muh Tamimuddin $\mathrm{H}$, "Pengenalan Media Pembelajaran Berbasis Mobile (Mobile Learning)", E-Learning, Jakarta, 2010

8. Madcoms, "Adobe Flash Cs6 Profesional". Yogyakarta, Andi Publisher, 2013

9. Nazzaruddin Safaat H, "ANDROID", Informatika, Bandung, 2012

10. Rusman, "Belajar dan pembelajaran Berbasis Komputer". Bandung: Alfabeta, 2012

11. Rinaldi Munir,"Pengamanan Data Dengan Metode LSB",Bandung, Andi,2010. 